\title{
Ethnic Fertility Differentials in Pakistan
}

\author{
Ali MuHAmMAD
}

\begin{abstract}
Pakistan is a country facing relatively high rates of population growth due to high fertility and decline in mortality rates. This is not only depleting scarce resources but also contributing significantly to environmental degradation. It is, therefore, desirable to know; why fertility rates in Pakistan remain high despite the nationwide family planning coverage since 1965? The objective of this study, therefore, is to establish trends and patterns of fertility among different ethnic groups (on the basis of languages spoken) in Pakistan. The study also explores the major reasons for different fertility behaviour. This is because; there are variety of languages spoken throughout the country having distinct norms, traditions and other customs which directly or indirectly influence fertility and fertility related decisions.

The study found that the Balochi or Brohi speaking women had the most children, Sindhi and Pushto speaking women are the women with the second highest fertility levels, Punjabis with the lowest and Urdu speaking almost matching them. The study attributes the high fertility levels among some ethnic groups to low level of education, lower age at first marriage, higher demand for children and greater value placed on number of children. It is also found that fertility levels are high among those ethnic groups who have little knowledge and less use of contraceptives. On the basis of findings, study provides guideline to policy-makers, planners and family planning personnel's for policy formation to facilitate reduction of fertility in particular context and to target specific sub-groups of population.
\end{abstract}

\section{INTRODUCTION}

For an effective policy implementation, it is of great relevance to study the fertility differentials by ethnicity in a country like Pakistan where there are variety of languages spoken throughout the country having distinct norms, traditions and other customs. It is because ethnicity and ethnic factors like ethnic attitude, ethnic identification and cultural practices influence reproductive behaviour [Wong (1985)]. Ethnicity is a significant factor of equal or sometimes even greater importance compared with the effect of other factors such as urban-rural residence, wife's education, husband's education and household income [Wong (1985)]. Moreover people with different ethnic belongings may have different ideas Islamabad. 
regarding fertility and fertility related decisions such as ultimate decision of age at first marriage, ideal or desired family size, sex preference and birth averted methods. All these factors directly or indirectly may influence fertility levels. This is the reason why ethnic fertility differentials are taken into account?

The main objectives of the study, therefore, are: (a) to examine the fertility differentials by ethnicity; and (b) justify the findings which would help to understand why fertility is higher among some ethnic groups compared with others. Establishing levels and patterns of fertility among different ethnic groups will provide guideline to policy-makers, planners and family planning personnel for policy formation to facilitate reduction of fertility in particular context and to target specific sub-groups of population.

\subsection{Data Source}

The data used is taken from the Pakistan Demographic and Health Survey (1990-91) for the analysis presented in the study. The survey was conducted from December 1990 to May 1991 on the national basis and provides national and provincial level data on population and health related issues in Pakistan. The survey had target to interview 8,019 ever-married women aged 15-49 years. However, 6,910 eligible women were identified and 96 percent were successfully interviewed. The survey, though have some limitations but provides a useful measure of ethnicity, languages spoken by the respondents.

\subsection{Methodology}

Ethnicity refers to a group identity [Hurst (1996)] and the linguistic groups maintain a certain degree of cultural identity [Casterline (1984)], therefore on the basis of languages spoken female respondents are divided into six main ethnic groups i.e.; Urdu, Punjabi, Sindhi, Pushto, Balochi or Brohi and Siraiki speaking women. All other females who spoke different languages are categorised as 'others'.

Tables presented in this study and Mean Number of Children Ever born, an indicator to measure fertility, are computed by cross-tabulation. Fertility patterns and levels among females of different ethnic groups are shown for all as well as are divided into two broad age groups named younger (15-30 year of age) and older (31-49 year of age) women and shown in Table 1. This is to compare the fertility patterns among young and old cohorts of different ethnic groups. The Table shows that 1691 of the Punjabi speaking women were interviewed with an almost equal proportion of younger (15-30) and older (31-49) women which was also similar for the Urdu speaking women. The numbers of Balochi, Brohi and Siraiki speaking women interviewed were very small with a greater (62 percent) percentage at younger ages. Some 55.1 percent of the Pushto speaking women interviewed were also young. 
Table 1

Percent and Absolute Number of Women by Languages Spoken, Pakistan 1991

\begin{tabular}{|c|c|c|c|c|c|}
\hline \multirow{2}{*}{$\begin{array}{l}\text { Languages } \\
\text { Spoken }\end{array}$} & \multicolumn{2}{|c|}{ Younger (15-30) } & \multicolumn{2}{|c|}{ Older (31-49) } & \multirow{2}{*}{$\begin{array}{c}\text { Total } \\
\text { Number }\end{array}$} \\
\hline & Number & Percent & Number & Percent & \\
\hline Urdu & 538 & 49.8 & 542 & 50.2 & 1080 \\
\hline Punjabi & 849 & 50.2 & 842 & 49.8 & 1691 \\
\hline Sindhi & 565 & 53.3 & 496 & 46.7 & 1061 \\
\hline Pushto & 882 & 55.1 & 718 & 44.9 & 1600 \\
\hline Balochi+Brohi & 268 & 62.0 & 164 & 38.0 & 432 \\
\hline Siraiki & 203 & 51.4 & 192 & 48.6 & 395 \\
\hline Others & 178 & 55.1 & 145 & 44.9 & 323 \\
\hline Total & 3483 & & 3099 & & 6582 \\
\hline
\end{tabular}

Source: Pakistan Demographic and Health Survey 1990-91.

\section{SOCIO-ECONOMIC CHARACTERISTICS}

Socio-economic characteristics of the population have significant implications for fertility and fertility related decisions. This section, therefore, covers the most important characteristics such as urban-rural residence, education and age at first marriage as these are of crucial importance in fertility analysis.

\subsection{Urban-Rural Residence}

It is observed, overall in Pakistan, that TFR has been lower for urban areas compared to that of rural areas for most of the fertility surveys [Rukanuddin (1988) and Muhammad (1996)] including Pakistan Fertility Survey (PFS) 1974-75, Pakistan Labourforce and Migration Survey (PLM) 1979-80, Pakistan Contraceptive Prevalence Survey (PCPS) 1984-85 and Pakistan Demographic and Health Survey (PDHS) 1990-91. It is, therefore, expected that urban-rural distribution of population by ethnicity would also effect fertility and fertility related matters. Table 2, shows to examine the distribution of women who spoke different languages by urban and rural residence so that findings can be justified.

The table shows that the majority (95 percent) of Urdu speaking surveyed population live in urban areas and should have lower fertility. Almost half (50 percent) of those who spoke Balochi or Brohi and Urdu were found living in urban and in rural areas. The majority (73.4 percent) of Siraiki speaking respondents live in rural areas. 
Table 2

Percentage of Women who Spoke Different Languages, by Their Socio-economic Characteristics, Pakistan 1991

\begin{tabular}{|c|c|c|c|c|c|c|c|}
\hline \multirow[b]{2}{*}{ Characteristics } & \multicolumn{7}{|c|}{ Languages Spoken } \\
\hline & Urdu & Punjabi & Sindhi & Pushto & Bal+Bro & Siraiki & Others \\
\hline \multicolumn{8}{|l|}{ Type of Residence } \\
\hline Urban & 95.1 & 48.3 & 34.0 & 46.3 & 49.1 & 26.6 & 31.6 \\
\hline Rural & 4.9 & 51.7 & 66.0 & 53.7 & 50.9 & 73.4 & 68.4 \\
\hline Total & 100.0 & 100.0 & 100.0 & 100.0 & 100.0 & 100.0 & 100.0 \\
\hline \multicolumn{8}{|l|}{ Educational } \\
\hline No Education & 46.5 & 68.4 & 88.2 & 88.3 & 94.4 & 89.1 & 82.0 \\
\hline Prim and Middle & 23.0 & 21.3 & 9.8 & 7.5 & 3.9 & 6.3 & 12.7 \\
\hline Sec and Higher & 30.6 & 10.3 & 2.0 & 4.2 & 1.6 & 4.6 & 5.3 \\
\hline Total & 100.0 & 100.0 & 100.0 & 100.0 & 100.0 & 100.0 & 100.0 \\
\hline \multicolumn{8}{|l|}{ Age at First Marriage } \\
\hline Less than 17 Years & 34.8 & 31.8 & 62.8 & 42.8 & 57.4 & 46.1 & 35.0 \\
\hline 17-19 Years & 29.5 & 33.8 & 17.8 & 25.6 & 23.4 & 20.0 & 34.7 \\
\hline 20-22 Years & 21.1 & 19.8 & 12.4 & 18.2 & 10.2 & 20.0 & 18.3 \\
\hline 23 Years and above & 14.5 & 14.7 & 7.0 & 13.5 & 9.0 & 13.9 & 12.1 \\
\hline Total & 100.0 & 100.0 & 100.0 & 100.0 & 100.0 & 100.0 & 100.0 \\
\hline $\begin{array}{l}\text { Median Age at } \\
\text { Marriage }\end{array}$ & 18 & 18 & 15 & 17 & 16 & 17 & 18 \\
\hline Total (Number) & 1080 & 1691 & 1061 & 1600 & 432 & 385 & 323 \\
\hline
\end{tabular}

Source: Pakistan Demographic and Health Survey 1990-91.

\subsection{Education}

It is proved and accepted Worldwide that education, especially among women, plays an important role lowering fertility. For example: Graff (1979, p. 106) says, 'education has a specific value of its own because literate people are more likely to adopt such measures (birth averted) than illiterate ones'. Caldwell (1980, p. 225) argues that 'the primary determinant of the timing of the onset of fertility transition is the effect of mass education on the family economy. Casterline (1984) stressed that the effect of education on fertility has been a central focus in the study of fertility determinants. Mahmood (1985) found that education and literacy effect fertility in several indirect ways, those factors include delayed age at first marriage, reduction in the desired family size and greater exposure to knowledge and favourable attitude towards family limitations. Many other researchers [Khan (1979); Mubashir (1989) and Sathar (1993)] found that women's' level of education inversely related with the ideal 
and desired family size. The study, therefore, examined the women with their level of education and found (see Table 2) that the women who spoke Urdu generally had higher education with almost 31 percent of them with secondary or higher and 46.5 percent without education. Punjabi speaking women had 68.4 percent uneducated and Pushto over a high, 88 percent with no schooling.

\subsection{Age at First Marriage}

Marriage patterns have been one of the most important factor playing an important role in the transition from high to low fertility. Because age at which a women enters into a marital union, the percentage of women who never marry, the duration for which marital union remains intact, the incidence of widowhood, divorce and marriage - all are significant factors in determining the fertility levels of a country and Pakistan is known to be a country with almost universal marriage [Shah (1986a), p. 347]. Therefore, low age at marriage and marriage stability contribute enormously to high levels of fertility. The most of the demographers [Casterline (1984); Sathar (1984) and Shah (1986a)] favours and proved that delayed marriages played an important role in slowing down population growth. It is, therefore, important to examine the percentage of women by age at first marriage of different ethnic groups.

It was found (Table 2) that the age at first marriage among Sindhi speaking women was the lowest compared to all other ethnic groups, with a median age at first marriage of only 15 years. This was similar for the Balochi or Brohi speaking women. Moreover, the majority of Pushto and Siraiki women were also found to marry before 17 years of age. A significant proportion of Urdu and Punjabi speaking women, however, were found to have married at later ages, more than 20 years of age.

\section{FERTILITY DIFFERENTIALS}

Fertility levels and patterns among younger, older and all women are shown in Table 3. Though the difference found was not significant however, the Balochi or Brohi found with the highest fertility compared to other ethnic groups. The second major group with high fertility were the Siraiki speaking women. Sindhi and Pushto speaking women had almost same fertility levels. Punjabis were found to have the lowest fertility with Urdu speaking almost matching them.

The table also shows the fertility patterns of younger and older women by different linguistic groups. Fertility levels found was the highest among younger women who spoke Balochi or Brohi language followed by the Urdu speaking women. The lowest fertility among younger women was found for those who spoke 
Siraiki. Among the older women, the Siraiki speaking women had the highest fertility followed by Blochi or Brohi and Pushto speaking women and the lowest who spoke Urdu.

Table 3

Mean Number of Children Ever Born to Younger and Older Women

by Languages Spoken, Pakistan 1991

\begin{tabular}{lccccccc}
\hline Age & Urdu & Punjabi & Sindhi & Pushto & Balo+Bro & Siraiki & Others \\
\hline All Ages & 4.04 & 3.93 & 4.27 & 4.24 & 4.56 & 4.31 & 3.88 \\
Younger (15-30) & 2.79 & 2.43 & 2.75 & 2.47 & 2.81 & 2.31 & 2.44 \\
Older (31-49) & 5.65 & 5.71 & 5.98 & 6.15 & 6.22 & 6.34 & 5.68 \\
\hline
\end{tabular}

Source: Pakistan Demographic and Health Survey 1990-91.

\section{FERTILITY PREFERENCES}

\subsection{Ideal Family Size}

It is observed in Pakistan that the most of the women have no ideal number of children and say 'up to God' when asked about family size desires and desired family size can play an important role because desire for more children have an important and powerful effect on fertility [Li (1991)]. However, several factors may influence family size desires. First, society can play an important role in determining fertility and fertility related decisions [Rukanuddin (1982) and Ross (1982)] as fertility is determined by the whole society and depends upon individual decisionmaking through norms and formation of taste. Second, the relative value of children may be another deciding factor in fertility related decisions. Third, gender differences may also play an important role in deciding family size because, as Mason and Anju (1987) argue, most of the information gathered through fertility surveys suggest that women consistently desire smaller families compared to their husbands as it is an important factor related to fertility levels. Finally; family type, parents and relatives may also influence fertility related decisions. It is, therefore, desirable to know what is the ideal family size of the women respondents who spoke different languages (see Table 4).

The table shows that the majority of women (80 percent) who spoke Balochi or Brohi have no ideal family size. A high (76 percent) percentage of Siraiki speaking women also had no ideal number of children. Women speaking Urdu and Punjabi had a much clearer idea about desired family size with over one quarter indicating four children. The Sindhi, Balochi or Brohi and Pushto speaking women tended to desire 5 or more children. 
Table 4

Ideal Number of Children by Women Respondents who Spoke

Different Languages, Pakistan 1991

\begin{tabular}{|c|c|c|c|c|c|c|c|c|}
\hline \multirow{2}{*}{$\begin{array}{c}\text { Languages } \\
\text { Spoken }\end{array}$} & \multicolumn{6}{|c|}{ Ideal Number of Children } & \multicolumn{2}{|c|}{ Total } \\
\hline & 1 & 2 & 3 & 4 & $5+$ & Up-to-God & $\%$ & No. \\
\hline$\overline{\text { Urdu }}$ & 0.6 & 14.6 & 11.4 & 27.1 & 8.1 & 38.2 & 100 & 1077 \\
\hline Punjabi & 0.2 & 6.4 & 10.3 & 26.1 & 9.4 & 47.6 & 100 & 1677 \\
\hline Sindhi & 0.2 & 3.5 & 2.4 & 8.3 & 11.7 & 73.9 & 100 & 1055 \\
\hline Pushto & 0.3 & 3.4 & 6.0 & 10.6 & 10.4 & 69.3 & 100 & 1574 \\
\hline Bal+Brohi & 0.2 & 0.9 & 0.9 & 7.1 & 10.8 & 80.0 & 100 & 425 \\
\hline Siraiki & - & 2.5 & 4.1 & 10.1 & 7.1 & 76.2 & 100 & 395 \\
\hline Others & - & 6.9 & 6.9 & 21.9 & 6.3 & 58.0 & 100 & 319 \\
\hline
\end{tabular}

Source: Pakistan Demographic and Health Survey 1990-91.

\subsection{Family Size Desires}

It is also shown in Table 5, what number of children a woman desire when she already has living children because it would also help to indicate the intentions of women towards fertility control. It is observed that the Balochi or Brohi and the Siraiki speaking women were more likely to desire more children even when they had 5 or more living children. The 'up to God' response was found strongest among Balochi or Brohi speaking women and least strong among the Punjabis who had living children. It can be argued that the majority of the Urdu speaking women reside in urban areas and are educated, hence they at least have a numeric response and tend to desire less children. The majority of Punjabis reside in Punjab, the more developed and the lowest fertility province in Pakistan, hence are more likely to desire a smaller family size compared to other ethnic groups.

'Up to God' response was found strongest among women who spoke Balochi or Brohi followed by Siraikis and Sindhis. Therefore, it can be argued that they have large family norms or are less likely to adopt such measures to avoid pregnancies and as a result experience high fertility.

\section{FAMILY PLANNING: ATTITUDE, KNOWLEDGE, AND PRACTICE}

The impact of fertility regulation variables is very significant, otherwise uncontrolled fertility will enormously contribute to population growth. Among the fertility regulation variables, the knowledge, access, availability and cost of access and use of contraception are the most important variables through which the use of contraception may be influenced [Zaki (1993)]. The availability and use of contraception can reduce fertility significantly by reducing the incidence of unwanted 
Table 5

Percentage of Women who Desire Child in Future, by Number of Living Children, Pakistan 1991

\begin{tabular}{|c|c|c|c|c|c|c|}
\hline \multirow{2}{*}{$\begin{array}{l}\text { Ethnicity/ } \\
\text { Living Children }\end{array}$} & \multicolumn{4}{|c|}{ Desire for Future Child } & \multicolumn{2}{|c|}{ Total } \\
\hline & Yes & No & Up-to-God & Other & $\%$ & No. \\
\hline \multicolumn{7}{|l|}{ Urdu } \\
\hline Less than 3 & 64.2 & 17.1 & 14.7 & 4.0 & 100 & 346 \\
\hline 3 to 4 & 26.5 & 56.1 & 15.0 & 2.4 & 100 & 287 \\
\hline 5 and More & 7.9 & 71.5 & 14.2 & 6.4 & 100 & 330 \\
\hline \multicolumn{7}{|l|}{ Punjabi } \\
\hline Less than 3 & 80.2 & 11.4 & 5.4 & 3.0 & 100 & 572 \\
\hline 3 to 4 & 31.4 & 56.1 & 9.3 & 3.2 & 100 & 462 \\
\hline 5 and More & 8.8 & 81.9 & 6.6 & 2.7 & 100 & 486 \\
\hline \multicolumn{7}{|l|}{ Sindhi } \\
\hline Less than 3 & 78.9 & 5.0 & 12.8 & 3.4 & 100 & 383 \\
\hline 3 to 4 & 40.1 & 25.7 & 28.3 & 5.9 & 100 & 272 \\
\hline 5 and More & 9.6 & 58.1 & 25.5 & 6.8 & 100 & 365 \\
\hline \multicolumn{7}{|l|}{ Pushto } \\
\hline Less than 3 & 70.4 & 9.2 & 14.5 & 6.0 & 100 & 601 \\
\hline 3 to 4 & 33.2 & 33.4 & 26.9 & 6.5 & 100 & 368 \\
\hline 5 and More & 9.8 & 54.9 & 28.7 & 6.7 & 100 & 541 \\
\hline \multicolumn{7}{|l|}{ Balochi+Brohi } \\
\hline Less than 3 & 67.8 & 2.6 & 23.7 & 5.9 & 100 & 152 \\
\hline 3 to 4 & 42.7 & 16.1 & 36.3 & 4.8 & 100 & 124 \\
\hline 5 and More & 18.8 & 27.5 & 44.2 & 9.4 & 100 & 138 \\
\hline \multicolumn{7}{|l|}{ Siraiki } \\
\hline Less than 3 & 81.7 & 4.3 & 11.6 & 2.4 & 100 & 164 \\
\hline 3 to 4 & 49.4 & 28.2 & 16.5 & 5.9 & 100 & 85 \\
\hline 5 and More & 13.6 & 72.0 & 11.4 & 3.0 & 100 & 132 \\
\hline \multicolumn{7}{|l|}{ Others } \\
\hline Less than 3 & 72.9 & 7.8 & 16.3 & 3.1 & 100 & 129 \\
\hline 3 to 4 & 40.0 & 32.7 & 14.5 & 12.7 & 100 & 55 \\
\hline 5 and More & 12.4 & 60.0 & 18.1 & 9.5 & 100 & 105 \\
\hline
\end{tabular}


births and improving the birth spacing. There are examples of many countries (e. g., China, Sri Lanka, and Indonesia), which have achieved low fertility levels by implementing a strong family planning policy. It is, therefore, important for a strong, comprehensive and effective implementation of a population policy to have some knowledge about the intentions of couples, belonging to different ethnic groups, towards these services.

Results show (Table 6), that a majority (almost 49 percent) of Balochi or

Table 6

Percentage of Women who Knew, Ever Used, and/or Currently Using a Contraception Method, by Ethnicity, Pakistan 1991

\begin{tabular}{|c|c|c|c|c|c|c|}
\hline \multirow[b]{2}{*}{$\begin{array}{l}\text { Contraceptive and } \\
\text { Languages } \\
\text { Spoken }\end{array}$} & \multicolumn{6}{|c|}{ Method of Contraception } \\
\hline & Mod & Trade & $\begin{array}{l}3 \\
3=1+2 \\
\text { Any }\end{array}$ & No Any & $\begin{array}{c}5=1+2 \\
+4 \text { or } \\
5=3+4 \\
\text { Total }(\%)\end{array}$ & Number \\
\hline \multicolumn{7}{|l|}{ Knowledge } \\
\hline Urdu & 60.8 & 32.9 & 93.7 & 6.3 & 100 & 1080 \\
\hline Punjabi & 52.0 & 31.2 & 83.2 & 16.8 & 100 & 1691 \\
\hline Sindhi & 50.1 & 16.7 & 66.8 & 33.2 & 100 & 1061 \\
\hline Pushto & 60.4 & 20.8 & 81.2 & 18.8 & 100 & 1600 \\
\hline Bal+Brohi & 37.3 & 14.1 & 51.4 & 48.6 & 100 & 432 \\
\hline Siraiki & 58.5 & 19.2 & 77.7 & 22.3 & 100 & 395 \\
\hline Others & 51.7 & 31.6 & 83.3 & 16.7 & 100 & 323 \\
\hline \multicolumn{7}{|l|}{ Ever Use } \\
\hline Urdu & 27.5 & 22.1 & 49.6 & 50.4 & 100 & 1080 \\
\hline Punjabi & 15.6 & 13.0 & 28.6 & 71.4 & 100 & 1691 \\
\hline Sindhi & 5.8 & 3.3 & 9.1 & 90.9 & 100 & 1061 \\
\hline Pushto & 11.8 & 4.3 & 16.0 & 84.0 & 100 & 1600 \\
\hline Bal+Brohi & 6.5 & 1.6 & 8.1 & 91.9 & 100 & 432 \\
\hline Siraiki & 6.6 & 6.3 & 12.9 & 87.1 & 100 & 395 \\
\hline Others & 15.2 & 6.2 & 21.4 & 78.6 & 100 & 323 \\
\hline \multicolumn{7}{|l|}{ Current Use } \\
\hline Urdu & 22.1 & 8.3 & 30.3 & 69.7 & 100 & 1042 \\
\hline Punjabi & 11.7 & 4.3 & 16.0 & 84.0 & 100 & 1605 \\
\hline Sindhi & 3.4 & 0.7 & 4.0 & 96.0 & 100 & 1041 \\
\hline Pushto & 8.3 & 1.7 & 9.9 & 90.1 & 100 & 1560 \\
\hline Bal+Brohi & 3.3 & 0.5 & 3.8 & 96.2 & 100 & 421 \\
\hline Siraiki & 4.9 & 2.1 & 7.0 & 93.0 & 100 & 388 \\
\hline Others & 12.7 & 1.6 & 14.3 & 85.7 & 100 & 308 \\
\hline
\end{tabular}

Source: Pakistan Demographic and Health Survey 1990-91. 
Brohi women had no knowledge about contraceptives. While most (93.7 percent) of the Urdu speaking women followed by the Punjabis had the knowledge of these methods. Ever use of contraceptive methods shows that the majority (49.6 percent) of Urdu speaking women had ever used any method. However, the Balochi or Brohi and Siraiki speaking women showed a very low level of use. The trend for current users by ethnicity is also similar as in the case of knowledge and ever use.

Finally, it is not hard to say that Urdu speaking women have more knowledge and higher use of contraceptives compared to other ethnic groups. The second major ethnic group appeared as a frequent users are the Punjabis and lowest Balochi or Brohi. Of particularly note, modern methods were more commonly used among the users than traditional one.

\section{CONCLUSION AND POLICY RECOMMENDATIONS}

The study found that the Balochi or Brohi had the most children. Sindhi and Pushto speaking women are the women with the second highest fertility levels and Punjabis with the lowest. The high fertility levels among some ethnic groups can be attributed to higher demand for children, lower age at first marriage and greater value placed on number of children. Moreover, low level of education and concentration of majority respondents of some ethnic groups in rural areas also contribute to their fertility levels. It is, however, surprising that Urdu speaking women had higher fertility compared to Punjabis despite the fact that more reside in urban areas and the most are highly educated.

As policy measures the study suggests that it will be useful to have a different policy with prevailing situation of each ethnic groups. In this regard women education is the most important factor as it has been playing a significant role in bringing down fertility of different nations. It is, therefore, suggested that educational facilities should be provided for those ethnic groups having a very high proportion without education.

It is difficult to raise and enforce the age at first marriage legally due to strong belief in Islamic law, customs and traditions of Pakistani societies. Therefore, a suitable policy is required to discourage early age at marriage. In this regard education and improvement in status of women can play an important role as women's education have a positive effect on age at first marriage [Mahmood (1985)].

Improved access to and availability of family planning services can significantly reduce fertility levels. The policy, therefore, should be adopted to spread these facilities overall the provinces and the places where there is need. It is also of crucial importance to have such a policy which match the supply and demand of family planning services. 


\section{REFERENCES}

Caldwell, John C. (1980) Mass Education as a Determinant of the Timing of Fertility Decline. Population and Development Review 6:2 225-255.

Casterline, J. (1984) Fertility Differentials in Pakistan. In I. Alam and B. Dineson (eds) Fertility in Pakistan: A Review of Findings from the Pakistan Fertility Survey. Voorburg Netherlands: International Statistical Institute.

Graff, Harvey J. (1979) Literacy, Education and Fertility, Past and Present: A Critical Review. The Population and Development Review 5:1 105-140.

Hurst, O. C. (1996) Pakistan Ethnic Divide. Studies in Conflict and Terrorism 19:2. San Bernardino, California: USA. California State University at San Bernardino.

Khan, M. A., and I. Siralgeldin (1979) Education, Income and Fertility in Pakistan. Economic Development and Cultural Change 27:3.

Li, Bohua (1990) Levels, Trends and Determinants of Fertility in China 1973-1988. Asia-Pacific Population Journal 5:2 3-16 Bangkok: Thailand.

Mahmood, Nushin, and Z. Khan (1985) Literacy Transition and Female Nuptiality : Implications for Fertility in Pakistan. The Pakistan Development Review 24:3\&4 1097-1106.

Mason, Karen O., and Anju M. Taj (1987) Differences between Women's and Men's Reproductive Goals in Developing Countries. The Population and Development Review 13:4 611-638.

Mubashir, Ali S. (1989) Determinants of Family Size Preference in Pakistan. The Pakistan Development Review 28:3 207-231.

Muhammad, Ali (1996) Seeking Explanations for High Fertility in Pakistan. Thesis submitted to fulfil the requirements of M.A. in Population and Human Resources at the University of Adelaide, Adelaide, South Australia.

National Institute of Population Studies (NIPS) (1992) Islamabad: Pakistan Institute for Resource Development/Macro International. Published Report of Pakistan Demographic and Health Survey 1990-91, Columbia, Maryland.

Ross, John A. (1982) International Encyclopaedia of Population 1: 275-286. New York: The Free Press.

Rukanuddin, A. Razaque (1982) Infant-child Mortality and Son Preference as Factors Influencing Fertility in Pakistan. The Pakistan Development Review 21:4 297-328.

Rukanuddin, A. Razaque, and Farooqi, M. N. I. (1988) The State of Population in Pakistan. Islamabad: National Institute of Population Studies.

Sathar, Zeba A. (1984) Does Female Education Affect Fertility Behaviour in Pakistan. The Pakistan Development Review 23:4 573-590.

Sathar, Zeba A. (1993) The Much Awaited Fertility Decline in Pakistan: Wiseful Thinking or Reality? International Family Planning Perspectives 19:4 142-146, New York. 
Shah, Nasara M. (1986) Changes in Female Roles in Pakistan: Are the Volume and Pace Adequate? The Pakistan Development Review 25:3 339-369.

Shah, Nasra M. (ed) (1986a) Pakistani Women: A Socioeconomic and Demographic Profile. Islamabad: Pakistan Institute of Development Economics. 23, 71, 95, 246, 293, 308, 326 pp.

Wong, Aline K., and Meng, Ng Shui (1985) Ethnicity and Fertility in Southeast Asia: A Comparative Analysis. Singapore: Institute of Southeast Asian Studies. (Research Notes and Discussion Paper No. 50.)

Zaki, Khalida P. and Nan E. Johnson (1993) Does Women's Literacy Affect Desired Fertility and Contraceptive Use in Rural-Urban Pakistan? Journal of Biosocial Sciences 25:4 445-54. Cambridge, England. 